\title{
Jogos e brincadeiras infantis na educação ateniense do Período Clássico
}

\author{
Childish games and plays in Athens during the Classical Age
}

Luana Neres de Sousa*

\begin{abstract}
Resumo: O reconhecimento da importância dos jogos e das brincadeiras no processo de interação social e de aquisição do conhecimento realizado por crianças pequenas não é exclusividade das sociedades contemporâneas. Ao analisarmos textos gregos antigos, como as Leis, de Platão, observamos que essas atividades recebem importantes reflexões acerca de sua relação com o processo educativo do futuro cidadão ateniense. Além da documentação textual, brinquedos e brincadeiras infantis são retratados em cerâmicas do período clássico, especialmente nas choes, vasos de uso exclusivo de crianças e relacionados ao contexto das Antestérias. $O$ objetivo deste artigo é analisar a maneira como os jogos e as brincadeiras são concebidos por Platão, nas Leis, bem como são representados em três exemplares de choes dos séculos V e IV a.C., visando compreender em que medida estas atividades estavam relacionadas ao processo educativo dos meninos atenienses deste período.
\end{abstract}

\begin{abstract}
Acknowledging the importance of games and plays in the social interaction process and knowledge acquisition made by small children isn't exclusive from contemporary society. Over the analysis of ancient greek texts, such as Plato's Laws, it's possible to observe that those activities receive important reflections about its relations with the educational process of the future Athenian citizen. Beyond text documentation, toys and infant plays are depicted in greek ceramic from the classical period, especially on choes, child's exclusive use vases and related to the context of the Anthesteria. The objective of this article is to analyse the way games and plays are conceived by Plato on Laws, also, how they are represented over three choes examples from centuries $V$ and IV B.C., objecting to understand in what measures those activities were related to the educational process of Athenian boys from this period.
\end{abstract}

\author{
Palavras-chave: \\ Jogos. \\ Brincadeiras. \\ Educação. \\ Infância. \\ Grécia Antiga.
}

\author{
Keywords: \\ Games. \\ Child plays. \\ Education. \\ Childhood. \\ Ancient Greece.
}

\footnotetext{
* Doutora em História pela Universidade Federal de Goiás. Professora efetiva da Rede Municipal de Educação de Goiânia. Pesquisadora vinculada ao Laboratório de Estudos sobre o Império Romano (Leir-GO) e ao Núcleo de Pesquisa em Sociedade, Educação e Cultura (NUSEC-IFG).
} 


\section{Introdução}

A partir das contribuições teóricas de Jean Piaget e Lev Vygotsky, ${ }^{1}$ a discussão, nos últimos anos, acerca da relevância dos jogos e das brincadeiras no desenvolvimento das crianças ganhou destaque na área da Educação, no Brasil, sobretudo após a elaboração e a implementação das Diretrizes Curriculares Nacionais da Educação Infantil (DCNEl, Resolução CNE/CEB n 5/2009) e da nova proposta da Base Nacional Comum Curricular (BNCC). Nestes documentos, a brincadeira assume importância basilar no processo de aquisição e de construção de conhecimento pela criança, haja vista proporcionar "experiências nas quais as crianças podem construir e apropriar-se de conhecimentos por meio de suas ações e interações com seus pares e com os adultos, o que possibilita aprendizagens, desenvolvimento e socialização" (BRASIL, 2017, p. 37).

A Base Nacional Comum Curricular defende que brincaré um direito da criança e que por intermédio da interação proporcionada por esse tipo de atividade, seja entre crianças com elas próprias ou com adultos, é possível que haja o seu desenvolvimento integral, uma vez que são trabalhados os sentimentos, os conflitos e suas frustrações (BRASIL, 2017, p. 37-38). Ao discorrer sobre os objetivos de aprendizagem e desenvolvimento para a Educação Infantil, a BNCC apresenta, nas habilidades EI02CG01, EI03CG02 e EI03CG03, a importância dos jogos e das brincadeiras no processo de aquisição pela criança (de zero a cinco anos e onze meses) de gestos e movimentos de sua cultura, no cuidado de si, no controle e adequação do uso de seu corpo, na escuta e recontagem de histórias e nas atividades artísticas (BRASIL, 2017, p. 47).

Em artigo recentemente publicado, ${ }^{2}$ destacamos que o conceito de "criança" está ligado ao desenvolvimento biológico do ser humano, enquanto "infância" é um conceito abstrato e que se modifica a partir da maneira como a sociedade em que as crianças estão inseridas se relaciona com elas (SOUSA, 2019, p. 2). Do mesmo modo, jogos e brincadeiras possuem significados distintos entre si e também em cada contexto no qual são concebidos.

Tizuko Morchida Kishimoto (2011, p. 15) afirma que definir o significado da palavra "jogo" não é uma tarefa fácil, haja vista as diferentes conjunturas às quais esta palavra pode estar relacionada, seja infantil, adulta ou política. A autora aponta que um mesmo

\footnotetext{
${ }_{1}^{1}$ Para um estudo mais aprofundado deste assunto, ver o artigo O advento da Base Nacional Comum Curricular sob as perspectivas teórico-epstemológicas de Piaget, Wallon e Vygotsky, de Jacqueline Fonseca de Queiroz e Luciano dos Santos (2019).

${ }^{2}$ Realizamos, no artigo Havia entre os atenienses do período clássico a ideia de infância? Uma possibilidade de análise do diálogo entre a cerâmica grega e a Filosofia (2019), uma discussão acerca da compreensão que os antigos atenienses possuíam sobre as especificidades das crianças no limiar de seu desenvolvimento, sobre a inexistência de um vocábulo único para o que hoje compreendemos por infância, bem como sobre o lugar que tal concepção ocupou na historiografia da Antiguidade nos últimos anos. Para mais detalhes, consultar o artigo citado.
} 
tipo de comportamento pode ser compreendido por jogo ou não e ressalta a importância de se respeitar o uso cotidiano do jogo ao se interpretar a linguagem a ele relacionada (KISHIMOTO, 2011, p. 17-19).

Torna-se necessária, assim, a distinção entre os conceitos de "jogo", de "brincadeira" e de "brinquedo". Kishimoto (2011, p. 20-21) se debruça sobre essa questão e conclui que "jogo" possui três níveis de diferenciação: o primeiro está relacionado ao significado por ele assumido através da linguagem; o segundo, se refere ao sistema de regras que permite identificar a existência de uma sequência estrutural; e, por fim, a materialização do jogo como artefato (por exemplo, um tabuleiro de xadrez). Já "brinquedo" é um objeto de relação íntima com a criança, caracterizado pela ausência de um sistema de regras preexistentes. Entendemos que, para a autora, o brinquedo é um objeto utilizado na ação da "brincadeira", conferindo-Ihe um caráter espontâneo em decorrência de seu uso indeterminado. Contudo, concordamos com Maria Aparecida Cória-Sabini e Regina Ferreira de Lucena (2012, p. 30), quando as autoras afirmam que uma brincadeira nem sempre necessita de um objeto específico (brinquedo) para que possa acontecer:

[...] no brincar há uma ausência de regras na organização das atividades. Assim, não há definição permanente de desempenhos, nem objetos específicos. Qualquer objeto pode representar, para a criança, tudo o que existe no cotidiano, na natureza e nas construções humanas. Por tais razões, o brincar é mais específico da infância e não se confunde com jogo.

Destarte, considerando que cada sociedade compreende de modo singular a relação da criança com o lúdico, problematizamos: que relevância os jogos e as brincadeiras infantis ocupavam no cotidiano dos meninos atenienses do período clássico (séculos $\mathrm{V}$ e VI a.C.) e em sua preparação para a vida adulta? ${ }^{3}$ No intuito de responder a esta questão, propomos a análise da obra Leis, do filósofo Platão, e de três cenas contendo crianças, impressas em cerâmicas de figuras vermelhas deste período, buscando elementos comuns e divergentes entre eles.

\section{Os jogos e brincadeiras no diálogo Leis, de Platão}

Ao analisar a documentação textual do período clássico, Mark Golden (2015, p. 11-12) constatou que não havia, na língua grega, um termo único utilizado para definir infância; ao contrário, diversas palavras eram empregadas para determinar as diferentes

\footnotetext{
${ }^{3}$ Por uma questão metodológica, trataremos, neste artigo, somente de brincadeiras realizadas por crianças do sexo masculino e oriundas de famílias atenienses abastadas. Ou seja, nossa análise não abarca a discussão sobre as meninas, as crianças estrangeiras ou os filhos dos escravizados.
} 
fases do desenvolvimento humano, ${ }^{4}$ dentre elas $\beta \rho \varepsilon \varphi о \varsigma$ (brephos, recém-nascido),

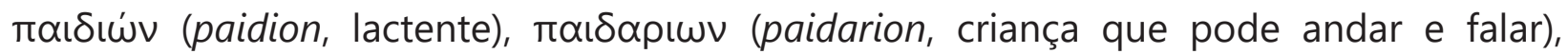

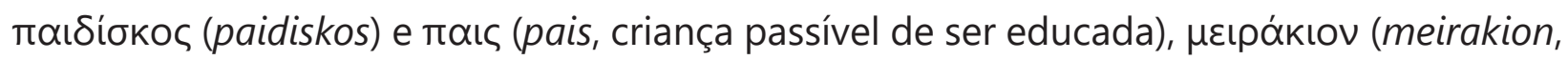
adolescente), veaviбкоৎ (neaniskos) e veavías (neanias, jovem adulto), dentre outros. Destes, os vocábulos que mais aparecem na documentação para determinar os primeiros anos de uma criança são brephos, paidion, paidarion e pais, sendo este último também utilizado para indicar as moças antes de se casarem e os escravos.

De maneira geral, para determinar o ato de brincar havia, no grego ático, os termos $\pi \alpha ı \delta ı \alpha$ (paidiá, brincadeira, jogo) e $\pi \alpha i ́ \zeta \omega$ (paízo, brincar, jogar, tocar um

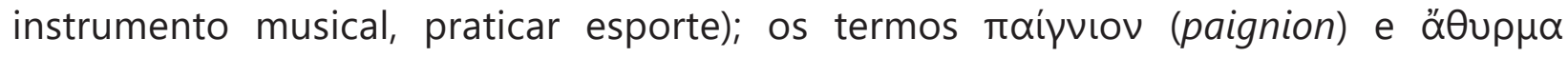
(athurma) designavam o que compreendemos por brinquedo. Stephen Kidd (2019) esclarece que, embora o verbo paízo esteja enraizado no substantivo pais (criança), não significa que a palavra fosse restrita a elas, haja vista paízo ser utilizada também para indicar algum tipo de recreação adulta. Segundo o autor (KIDD, 2019, p. 20), "a conexão entre 'criança' e 'brincar' é simplesmente mais evidente para o grego do que para muitas outras línguas". Em Platão, encontramos paidiá quando o filósofo se refere às brincadeiras infantis e paízo ao entretenimento amadurecido.

O debate sobre a importância dos jogos e das brincadeiras infantis nas obras de Platão apresenta-se associado às reflexões sobre a educação em Atenas, sobretudo no diálogo Leis (Nómol, Nomoi), ${ }^{5}$ sua última e mais extensa obra. Nela, Platão discorre sobre um Estado ideal no qual uma série de leis, elaboradas por homens virtuosos, deveria reger as ações dos cidadãos no intuito de que estes garantissem a defesa do bem comum em sobreposição aos seus interesses individuais. ${ }^{6}$ Ainda que o ensino das crianças não se converta no tema principal deste diálogo, o filósofo apresenta os pilares da sua proposta de educação nos Livros I, II e VII, aprofundando o assunto neste último. Sócrates não

\footnotetext{
${ }^{4}$ De modo geral, não há consenso entre os autores gregos a respeito da idade exata que delimita o início e o fim de cada uma das fases apresentadas. Neste artigo, consideraremos a divisão etária proposta por Hipócrates e citada por Fílon de Alexandria na obra De opifício mundi, que divide o desenvolvimento do indivíduo do sexo masculino em sete ciclos de sete anos, sendo os quatro primeiros: paidion (até que nasçam os dentes: 7 anos), pais (até que passe a produzir sémen: 14 anos), meirakion (até que nasça a barba: 21 anos), neaniskos (até o desenvolvimento corporal completo: 28 anos) (Fílon, De opifício mundi, 105).

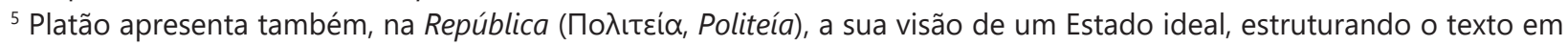
torno de uma narração de Sócrates sobre diversos temas que culminam na questão da essência da justiça. A temática infantil aparece especialmente no Livro II, ancorada em dois pilares básicos: "ginástica para o corpo, música e poesia para a alma" (Respublica, II, 376c-377c). Todavia, neste artigo, focaremos nossa análise especialmente em Leis, por concordarmos com Carlos Humberto Gomes (2014, p. 12) de que as reflexões platônicas aparecerem neste diálogo mais adaptadas à realidade.

${ }^{6}$ Пoגítnc (polítes) é o termo grego para cidadão. O direito à cidadania, em Atenas, pertencia somente aos homens, filhos de pai e mãe de origem ateniense; estavam excluídas as mulheres, os estrangeiros e os escravos. As duas principais atividades de um cidadão durante o período clássico eram defender os interesses da polis em situações de guerra e também durante sua atuação nas deliberações na assembleia (MOSSÉ, 2004, p. 242).
} 
aparece como personagem e o diálogo realizado entre um ateniense anônimo, ${ }^{7}$ o cretense Clínias e o espartano Megilo é ambientado em Creta.

Para que possamos compreender a relevância das brincadeiras na educação das crianças pequenas, inicialmente é preciso interpretar a proposta educacional platônica contida nas Leis. A definição de educação que irá perpassar toda a obra é apresentada por Platão por meio do personagem Ateniense, em um diálogo com Clínias, logo no Livro I:

Em primeiro lugar, nossa reflexão requer que definamos a educação (paideía) e descrevamos seus efeitos [...]. ${ }^{8}$ Mas é imperioso que não deixemos que nossa definição de educação permaneça vaga, pois atualmente quando censuramos ou elogiamos a formação de um indivíduo humano, definimos um como educado e um outro como não-educado, a despeito deste último poder ser extraordinariamente bem educado no comércio como mascate ou como um piloto de embarcação, ou ainda em alguma outra ocupação similar. Mas nós, naturalmente, na presente discussão não estamos assumindo o parecer que coisas como essas constituem educação: a educação a que referimos é o treinamento desde a infância na virtude, o que torna o indivíduo entusiasticamente desejoso de se converter num cidadão perfeito, o qual possui a compreensão tanto de governar quanto de ser governado com justiça (Platão, Leges, I, 643a; c-e).

A partir da apreciação do trecho destacado, inferimos que a proposta de educação platônica presente em Leis está ancorada na constituição do cidadão virtuoso (kalokagathos) e não visa somente aos meninos da aristocracia, mas engloba também os filhos dos cidadãos menos abastados, que deveriam receber, além do conteúdo técnico de sua futura ocupação, lições capazes de despertar neles a virtude e o autocontrole.

De caráter exclusivamente masculino, a paideia praticada em Atenas era composta por aulas de leitura, escrita, música e atividades físicas oferecidas aos meninos maiores

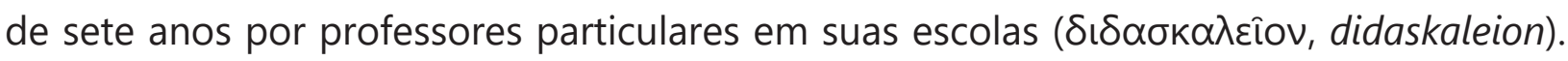
Embora fosse supervisionada pelo Estado, não havia, neste período, ensino público em Atenas. No diálogo Protágoras, Platão esclarece que os filhos dos ricos ingressavam na escola com menos idade e nela permaneciam por mais tempo que os filhos dos cidadãos mais pobres, complementando que os artesãos passam de pai para filho o conhecimento de sua arte (Platão, Protagoras, 326c; 328a). A este respeito, Giuseppe Cambiano (1994, p. 80) ressalta que os filhos dos cidadãos menos abastados e que não possuíssem escravos poderiam receber também instruções para o trabalho, geralmente oferecidas pelo pai, que poderiam ser artesanais ou no campo.

\footnotetext{
${ }^{7} \mathrm{Na}$ introdução de sua tradução de Leis para a Língua Portuguesa, Carlos Humberto Gomes afirma que a suposição mais adequada para a identidade do Ateniense é de que se trate do próprio Platão e não de Sócrates, haja vista este ter sido nomeado em outros diálogos (GOMES, 2004, p.13-14).

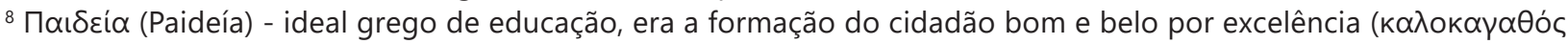
- kalokagathós).
} 
Durante o período clássico, a educação das crianças menores de seis anos ocorria exclusivamente no ambiente doméstico e era oferecida pela mãe e pelas amas

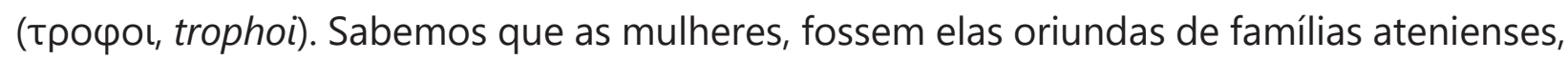
estrangeiras ou escravas, não participavam da paideia e não recebiam nenhuma outra espécie de educação formal; deste modo, não conheciam de maneira adequada os preceitos necessários à preparação dos meninos para o ingresso na vida política e social em Atenas. Platão era filósofo e, como tal, se sentia compelido a refletir sobre a educação das crianças pequenas, justamente por não concordar com a forma pela qual esta era realizada em seu tempo. Ao propor um modelo de educação em que após os seis anos as meninas também participassem de aulas de manejo de armas e exercícios físicos, Platão reconhece que as mulheres possuíam papel importante na formação e na sanção das crianças enquanto exerciam a função de cuidadoras delas. Sobre essa educação exclusivamente doméstica, anterior à paideia, Platão apresenta, por meio de um discurso proferido pelo personagem Protágoras, a forma como ela ocorria:

\begin{abstract}
Ensinam a criança e a corrigem desde muito pequena até o último dia de suas vidas. Assim, até que uma delas compreenda o que é dito, a ama de leite, a mãe, o pedagogo ${ }^{9}$ e o próprio pai se esforçam muito para que ela possa se tornar melhor; através de cada ato e palavra ensinam para mostrar-lhe o que é justo e injusto, que uma coisa é nobre, outra desprezível, uma sagrada, outra profana, e que se deve fazer isso e não aquilo. Se ela prontamente obedece, excelente; mas se não, eles tratam-na como um pedaço dobrado e trançado de madeira e a endireitam-na através de ameaças e golpes. Após isso, eles enviam o menino para a escola e dizem ao mestre que este se dedique mais a boa conduta de seu filho que ao ensino da leitura, da escrita e da cítara (Pl., Prt., 325c). ${ }^{10}$
\end{abstract}

Acerca dos conteúdos oferecidos pelas amas e mães às crianças muito pequenas, Platão indica, no Livro II da República, a existência de narrativas e contos que, segundo o filósofo, nem sempre eram adequados (PI., Resp., II, 376c-377c). Para castigar e amedrontar os menos obedientes, as mães e amas empregavam histórias muitas vezes assustadoras, como a de Lâmia, monstro feminino devorador de crianças. Segundo Pierre Grimal (1992, p. 265-266), havia várias lendas sobre Lâmia. A mais utilizada no contexto infantil se referia a uma jovem da Líbia que se apaixonou por Zeus e com ele teve alguns filhos. Hera, como forma de vingança, causava sofrimento à jovem cada vez que esta dava à luz, matando sua prole. Em desespero, Lâmia isolou-se em uma caverna, tornando-se um monstro, que, por inveja, tirava os filhos das mães e os devorava.

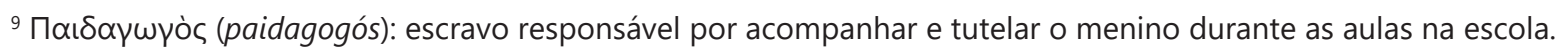

${ }^{10}$ Tradução nossa a partir do grego.
} 
Ainda sobre a ação das amas na educação das crianças pequenas, Platão afirma, no Livro VII das Leis, que sua inabilidade ultrapassava os limites intelectuais, com reflexos inclusive no uso inadequado da mão direita e da mão esquerda:

No que diz respeito às mãos (já que, em relação aos pés e aos membros inferiores, diferença alguma poderá, quanto aos respectivos movimentos, ser notada), e a falta de discernimento por parte das amas e das mães tem sido a causa de nos termos tornado, por assim dizer, deficientes (Pl., Leg., VII, 794 c-e).

Após a análise dos textos selecionados, concluímos que, para Platão, era necessário acompanhar de perto o conteúdo oferecido às crianças muito pequenas, no intuito de não comprometer a excelência de sua futura atuação como cidadão, seja em relação à educação intelectual ou à física. Por esta razão, acreditamos que o filósofo tenha se dedicado com tanto afinco a orientar sobre como deveria ser a educação das crianças, haja vista reconhecer, nessa faixa etária, o fundamento para a formação de um adulto moderado e de conduta exemplar.

Após refletirmos sobre o conceito de paideia em Atenas e sobre a definição de educação proposta em Leis, analisaremos mais de perto a questão dos jogos e das brincadeiras presente no diálogo. Platão esclarece, no Livro I, que a prática de qualquer atividade levaria o homem à excelência, independentemente de sua natureza, sendo necessário que, desde criança, essa experiência fosse prazerosa. A importância atribuída à brincadeira no processo de formação dos meninos é apresentada por Platão durante um diálogo entre o Ateniense e Clínias, conforme se segue:

O que afirmo é que todo homem que pretenda ser bom em qualquer atividade precisa dedicar-se à prática dessa atividade em especial desde a infância, utilizando todos os recursos relacionados a sua atividade, seja em seu entretenimento, ${ }^{11}$ seja no trabalho. Por exemplo, o homem que pretende ser um bom construtor necessita (quando menino) entreter-se brincando de construir casas, bem como aquele que deseja ser agricultor deverá (enquanto menino) brincar de lavrar a terra. Caberá aos educadores dessas crianças supri-las com ferramentas de brinquedo moldadas segundo as reais. Além disso, dever-se-á ministrar a essas crianças instrução básica em todas as matérias necessárias; sendo, por exemplo, ensinado ao aprendiz de carpinteiro sob forma de brinquedo o manejo da régua e da trena, àquele que será um soldado como montar e demais coisas pertinentes. E assim, por meio de seus brinquedos e jogos, nos esforçaríamos por dirigir os gostos e desejos das crianças para a direção do objeto que constitui seu objetivo principal relativamente à idade adulta. Em primeiro lugar e acima de tudo, a educação, nós o asseveramos, consiste na formação correta que mais intensamente atrai a alma da criança durante a brincadeira para o amor daquela atividade da qual, ao se tornar adulto terá que deter perfeito domínio (Pl., Leg., 643b-d).

\footnotetext{
${ }^{11}$ Platão utiliza, no texto original, o termo paízo.
} 
Para Platão, independentemente da função ocupada pelo cidadão na pólis, era indispensável que este recebesse uma formação adequada desde a mais tenra idade, sendo notório, na passagem acima, o valor das brincadeiras neste processo. De acordo com a proposta platônica, ficaria a cargo do educador providenciar utensílios que proporcionassem à criança a oportunidade de, através da mímesis ( $\mu \bar{\imath} \mu \eta \sigma \iota \varsigma)$, simular as ações que desempenharia na vida adulta. É através da prática conferida pela brincadeira que a criança se aperfeiçoaria em sua futura ocupação.

Um ponto importante a ser destacado é que Platão utiliza, em Leis, tanto o termo paidiá quanto paízo. Entendemos que, ao utilizar o primeiro, o filósofo se refere às brincadeiras espontâneas, cujas regras são criadas pelas próprias crianças; e paízo é empregado ao se referir aos divertimentos do homem já formado. É interessante pontuar que Platão não apresenta, em Leis, o nome ou a descrição de nenhum dos jogos infantis praticados em sua época, pois inferimos que ele atribuía valor à ação criativa das crianças empregada na formulação dessas atividades e, consequentemente, ao seu processo educativo. Outra explicação para que ele não defina essas características é que, como elas deveriam ser formuladas pelas crianças, o filósofo não se ocupa em descrever tais regras. Essa perspectiva de análise se distingue da apontada por Henri Marrou (1990, p. 225), que interpreta paidiá como futilidade para a sociedade grega. O que inferimos com base na obra de Platão é que as brincadeiras não eram concebidas como algo fútil, tendo em vista receberem do filósofo importante atenção e o reconhecimento de seu vínculo com a ação produtiva das crianças.

Refletindo acerca do lugar ocupado pelas brincadeiras na Educação Infantil brasileira, Celso Antunes (2014, p. 30) afirma que as crianças até os três anos não são capazes de perceber a diferença entre diversão e trabalho, sendo este o motivo pelo qual adoram ajudar os pais nos afazeres domésticos. Para Antunes, o educador desempenha, na Educação Infantil, papel fundamental na intersecção entre a brincadeira e as reflexões sobre ela. No caso de Atenas, Platão agia no sentido de orientar seu leitor sobre a melhor forma de aproveitar o interesse e a disposição das crianças no exercício de sua formação, para que os jogos e brincadeiras não se convertessem em meros passatempos. A questão específica dos jogos e brincadeiras no processo de aprendizagem dos meninos reaparece no diálogo de maneira mais especificada no Livro VII, no qual o filósofo esclarece que:

A formação do caráter da criança de mais de três anos e até seis exigirá a prática de jogos: ${ }_{i}^{12}$ neste período se fará o uso do castigo a fim de impedi-la de ser indolente [...]. Para crianças dessa idade, há jogos que nascem do próprio instinto natural e elas os inventam elas mesmas, sempre que estão juntas. Logo que atingirem

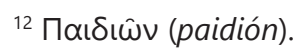


os três anos, todas entre três e seis anos terão que ser reunidas nos templos dos povoados, reunindo-se no mesmo lugar as que pertençam aos mesmo povoado [...]. Após os seis anos deverá haver uma separação dos sexos, meninos convivendo com meninos e meninas com meninas. Entretanto, tanto meninos quanto meninas passarão a receber instrução; os meninos aprenderão equitação, o manejo do arco, o arremesso do dardo e da funda; as meninas também, por pouco que se prestem a isso, deverão participar das lições, especialmente durante aquelas que se referem ao manejo de armas (Pl., Leg., VII, 793d-794d).

Novamente a questão das brincadeiras ocupa importante espaço na discussão platônica acerca da educação das crianças. O termo utilizado por Platão, no texto original, é paidiá, apontando a importância da brincadeira para a formação do caráter da criança entre os três e os seis anos e ressaltando o caráter produtivo dessa atividade ao afirmar que as próprias crianças elaboravam suas brincadeiras quando juntas. No trecho acima, o filósofo ainda amplia sua reflexão ao incluir as meninas em sua proposta educativa. Inferimos que, ainda que traga proposições para um Estado idealizado, Platão as elabora a partir das inquietações causadas por sua realidade. Conforme discutido anteriormente, as meninas eram excluídas da paideia e o filósofo via falhas nesse aspecto. É importante esclarecer que Platão propõe às meninas o ensino do manejo de armas, atividade de exercício prático, e não uma educação de caráter intelectual.

Segundo Albin Lesky (1995, p. 564), "em As Leis a educação é considerada uma grande força, ainda que não a única [...]. Elas [as leis] devem convencer os cidadãos de sua justeza e utilidade [...] e promover assim o conhecimento em vez da obediência cega". É possível constatar que a preocupação de Platão, em Leis, está em oferecer aos futuros cidadãos, desde a mais tenra idade, uma educação que os capacitasse a refletir e analisar o contexto no qual estivessem inseridos, para que assim as decisões tomadas na assembleia ateniense por estes quando adultos fossem as mais justas possíveis.

$\mathrm{O}$ ato de brincar proporciona à criança o exercício das habilidades de conhecer e respeitar regras, imprescindíveis no exercício de sua vida adulta, "assim como trocam entre si e com a sociedade as representações e os significados que lhes são atribuídos" (BRASIL, 2017, p. 220). Especialmente no contexto aqui analisado, as brincadeiras ocupavam, para Platão, um papel de suma importância no processo educativo, uma vez que proporcionavam ao menino um modelo que deveria ser seguido no futuro.

Notamos que, em virtude de sua posição privilegiada na sociedade, está intrínseco, no pensamento de Platão, que cada homem desempenharia um papel social determinado por sua origem, não sendo possível ao cidadão de menos posse ascender de status. Para o filósofo, o filho do agricultor, ao brincar, se habituaria desde cedo à atividade no campo e não almejaria ocupar outra função que não esta. Tal ideia fica explícita na passagem 
"por meio de seus brinquedos e jogos, nos esforçaríamos por dirigir os gostos e desejos das crianças para a direção do objeto que constitui seu objetivo principal relativamente à idade adulta" (PI., Leg., 643b-d). Entretanto, é preciso destacar que essa consciência do caráter pedagógico dos jogos não necessariamente era contemplada pelas crianças, pois, conforme sinaliza Kishimoto (2011, p. 28):

Entende-se que o jogo, por ser uma ação voluntária da criança, um fim em si mesmo, não pode criar nada, não visa a um resultado final. O que importa é o processo em si de brincar que a criança se impõe. Quando ela brinca, não está preocupada com aquisição de conhecimento ou desenvolvimento de qualquer habilidade mental ou física.

Concordamos com a afirmação de Kishimoto (2011) sobre a inexistência de um interesse pedagógico por parte da criança nas brincadeiras em que ela esteja envolvida. Inferimos que, no contexto específico de Atenas no período clássico, por mais que as crianças se divertissem em suas atividades cotidianas, Platão julga que as brincadeiras e os jogos não deveriam se converter em mera distração, pois estavam inseridos em um contexto educativo. Entendemos que a reflexão sobre o caráter pedagógico das brincadeiras e sua relação com a formação dos meninos atenienses não era uma questão habitual aos pais, mas Platão, como filósofo, era alguém que pensava a sociedade de um ponto de vista distinto da maioria dos cidadãos.

Realizadas as considerações sobre a proposta educacional de Platão para as crianças pequenas, analisaremos a seguir como as brincadeiras infantis são retratadas pelos pintores áticos do período clássico, buscando compreender em que medida tais imagens se aproximam ou se distanciam da visão platônica sobre a importância do lúdico no cotidiano dos meninos atenienses.

\section{Representações de jogos e brincadeiras na cerâmica ática}

Embora não possuíssem direitos políticos ativos em decorrência de sua inabilidade bélica e retórica, os meninos atenienses em formação participavam, desde seu nascimento, de atividades religiosas da pólis. Quando recém-nascidos, eram levados a dar uma volta em torno da lareira consagrada a Héstia, ${ }^{13}$ validando assim sua inserção no seio doméstico. Conforme demonstra Mario Vegetti (1994, p. 231), desde cedo as crianças estavam inseridas em uma experiência religiosa muito peculiar, que se caracterizava pela relação de proximidade entre os homens e os deuses. Nesse sentido, cerimônias religiosas

${ }^{13}$ Deusa do lar, filha de Crono e Reia, irmã de Zeus e de Hera (GRIMAL, 1992, p. 227). 
ocupavam importante papel como ritos de passagem na vida dos gregos de modo geral, e dos atenienses de maneira particular. Greta Ham (1999) e Robert Garland (2013) atestam que, embora as interpretações acadêmicas acerca dos ritos de passagem atenienses se concentrassem na mudança da adolescência para a vida adulta, uma importante cerimônia de transição ocorria quando o menino tinha em torno dos três anos: sua participação nas Antestérias, festival celebrado em homenagem a Dioniso no início da primavera, durante

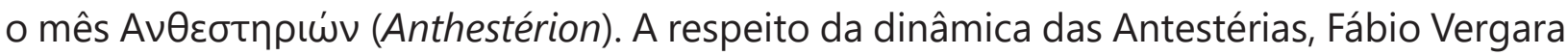
Cerqueira (2011, p. 153) esclarece que:

[...] a festividade transcorria ao longo de três dias, englobando rituais e crenças bastante distintos, em muitos casos independentes uns dos outros: o dia da Pithoigía, o das Khóes e o dos Khýtroi. Estas denominações relacionam-se aos tipos de vasos usados em rituais realizados ao longo destes dias: os pithoí são grandes recipientes cerâmicos usados na fermentação e conservação do vinho, equivalentes funcionalmente aos barris de madeira que surgiram no mundo imperial romano; as khóes são jarros com bucal arredondado usados em libações, sendo que as khóes em tamanho miniatura eram destinadas às crianças que participavam dos festejos das Antestérias; os khýtroi eram recipientes cerâmicos, análogos à marmita, usados no último dia das Antestérias, cheios de legumes crus, como oferenda a Dioniso e Hermes.

Conforme observamos, o segundo dia do festival era dedicado especialmente às crianças. Os meninos recebiam uma coroa de flores e uma chous em miniatura, ${ }^{14}$ que poderia ser utilizada para provar suas primeiras gotas de vinho. Esta festividade era tão importante que foi encontrada uma chous em um túmulo com a inscrição "um daimon chegou antes da Choes", dando a entender que o garoto havia falecido antes de sua participação na festa (GARLAND, 2013, p. 212). Greta Ham (1999, p. 208) defende a hipótese de que a participação das crianças no festival das Choes determinava o momento em que, capazes de compreender a linguagem, os meninos passavam dos cuidados exclusivos das mulheres, no espaço interno do oikos, para os cuidados de um pedagogo. ${ }^{15}$

John Oakley (2013) afirma que as choes de figuras vermelhas são as fontes mais importantes sobre as crianças atenienses no século $V$ a.C. Muito populares a partir de 430 a.C., foram localizados mais de mil exemplares de choes em túmulos infantis contendo imagens de crianças pequenas (sendo as do sexo masculino muito mais numerosas que as do sexo feminino), geralmente bebês engatinhando ou meninos brincando com

\footnotetext{
${ }^{14}$ Chous (Xoûc; pl. choes): vaso de forma arredondada e com abertura em trifólio. A chous é um dos dez tipos de oinochoe (oıvoxón; pl. oinochoai) identificados por Beazley, tipo de jarro utilizado para servir vinho, cujo nome é constituído pela junção dos termos oinos (vinho) e cheo (eu despejo). Descrição disponível em https://www.beazley.ox.ac.uk/tools/ pottery/shapes/oinochoe.htm. Acesso em 12/01/2020.

${ }^{15}$ Conforme apresentado anteriormente, Platão relata, em Protágoras, que o paidagogos era um dos responsáveis pela formação do menino enquanto esse ainda não tivesse ingressado na escola (Pl., Prt., 325c).
} 
carrinhos, bolas e animais de estimação, como cães, lebres, cabras e pássaros (OAKLEY, 2013, p. 166).

Acerca dessas representações, Maria Stilund Sommer (2011, p. 146) aponta que brincar era uma realidade, ainda que as cenas impressas nas cerâmicas possam não representar de maneira realística a forma como as brincadeiras aconteciam. É preciso destacar que as análises desse artigo se concentram nas atividades realizadas pelas crianças provenientes das famílias abastadas de Atenas, haja vista disporem de tempo ocioso para desenvolverem suas brincadeiras e de recursos financeiros para a aquisição de brinquedos, que se tratavam de artefatos de custo significativo. Encontramos um exemplo do valor monetário de um brinquedo na comédia As Nuvens (861-864), de Aristófanes: ao tentar convencer Fidípedes a se tornar aluno de Sócrates, Estrepsíades relata que gastou todo o dinheiro recebido como heliasta na compra de um carrinho quando o filho tinha seis anos. ${ }^{16}$ Além disso, Sommer (2011, p. 152) nos alerta para o fato de que:

Provavelmente, nem todas as crianças tiveram uma infância lúdica. Talvez algumas, especialmente as crianças pobres e escravas, tiveram uma vida difícil com o trabalho desde uma tenra idade, evitando assim a alegria de brincar. No entanto, as evidências materiais mostram até agora que algumas crianças brincavam e estavam envolvidas em interações cuidador-criança.

Esta observação da autora nos remete à passagem presente em Leis, na qual Platão orienta que a brincadeira, como treino para a vida adulta, deveria fazer parte da realidade da criança pequena (PI., Leg., I, 643a-c). É muito provável que o filósofo tenha observado que as crianças que obtinham o mínimo de prazer na execução do seu trabalho o realizavam de maneira mais proveitosa. Ademais, é fundamental esclarecer que nem toda brincadeira necessita de objetos específicos (brinquedos) para ser realizada e retomar que Platão sinaliza a criação de jogos pelas próprias crianças a partir de suas competências (PI., Leg., VII, 793e-794a). Desse modo, acreditamos que, por mais que necessitassem trabalhar com o pai para garantir a subsistência de sua família, as crianças menos abastadas também brincavam, mesmo que não o tempo todo, pois, conforme afirma Sommer (2011, p. 146), "brincar faz parte da infância".

Retornando à questão da maneira como os jogos e as brincadeiras são retratados na cerâmica ática, analisaremos a seguir três exemplares de choes de figuras vermelhas do período clássico. A primeira chous (Figura 1), sem autoria definida, traz, no centro da imagem, um bebê (paidion) sentado de frente para o observador, em um assento de uso

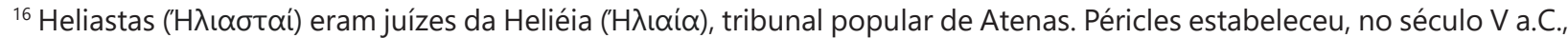
que a cada sessão o heliasta recebesse o pagamento de dois óbolos, passando a receber três óbolos posteriormente (MOSSÉ, 2004, p. 160-161).
} 
exclusivo infantil semelhante à cadeira de figuras negras P18010 conhecida como sella cacatoria. ${ }^{17}$ A parte superior do seu corpo está levemente virada para a esquerda. Em sua

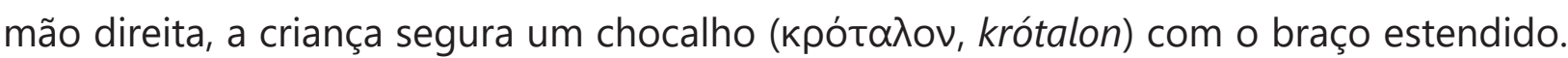
Suas pernas estão ligeiramente tortas, o que, para Kathleen Lynch e John Papadopoulos (2006, p. 19) indica que estejam em movimento. No chão, é possível apreciar do lado

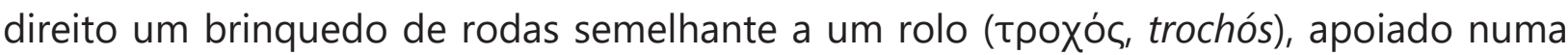
parede e, do lado esquerdo, uma oinochoe adornada com duas faixas.

Figura 1 - Chous de figuras vermelhas, de aproximadamente 440-425 a.C.

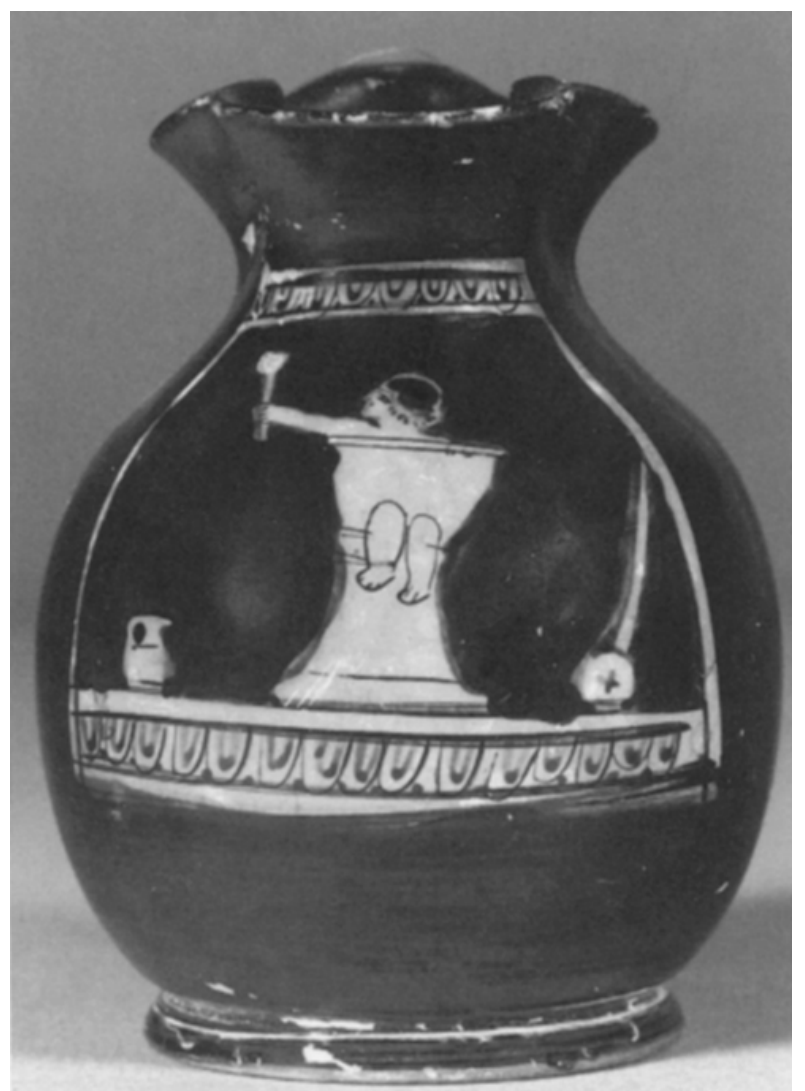

Atualmente no Museu Britânico de Londres (1910.6-15.4). Fonte: LYNCH; PAPADOPOULOS (2019).

Identificamos, nesta cena, dois tipos de brinquedos: um rolo e um chocalho. Inferimos que, por se tratar de uma criança muito pequena, ela ainda não conseguiria brincar sozinha com o rolo representado na imagem, mas, por já conseguir ficar sentada, poderia se divertir com outra criança maior ou mesmo com um adulto. ${ }^{18}$ Sommer (2011, p. 146-147) afirma que os chocalhos produzidos em terracota, muitas vezes em formato

\footnotetext{
${ }^{17}$ Para maiores detalhes acerca da cadeira P18010, consultar o artigo de Kathleen M. Lynch e John Papadopoulos (2006) citado na bibliografia.

${ }^{18}$ Dispomos, na atualidade, de diversas choes que retratam imagens semelhantes ao trochós representado acima. Para outras imagens de meninos brincando com este objeto, consultar Neils e Oakley (2003).
} 
de porco, poderiam ser manuseados pela própria criança ou por um adulto. O som que produziam ao serem sacudidos divertiam e estimulavam os bebês, sendo também utilizados com o objetivo de espantar os maus espíritos. A existência desse artefato arqueológico e sua representação na cerâmica indica que a sociedade se preocupava em estimular as crianças e em atender suas necessidades. Como exemplo, podemos citar a afirmação de Platão (Leg., VII, 792b) de que as amas se valiam do choro e dos gritos dos bebês para saber o que lhes oferecer no intuito de atender seus desejos. A partir da ausência da representação de choro na cena, da expressão de satisfação contida em seu rosto e da indicação do movimento das pernas, inferimos que a criança retratada na Figura 1 se diverte e se movimenta alegremente enquanto brinca com o seu chocalho.

As próximas choes trazem imagens de meninos um pouco maiores que o representado na figura anterior. Na Figura 2, de autoria desconhecida, observamos um menino puxando um rolo de brinquedo com a mão esquerda e com a direita estendida em direção a um pilar hermaico, que traz as feições de um menino, ${ }^{19}$ algo não muito comum. Podemos relacionar o teor da cena ao contexto das Antestérias pela presença da criança brincando com seu carrinho, pela presença do altar, da herma e de uma olpeno chão, ${ }^{20}$ do lado direito.

\footnotetext{
${ }^{19}$ Descrição realizada por Alexandra Kardianou-Michel e Miniature Attic Red-Figure Oinochoe. Louvre - Department of Greek, Etruscan, and Roman Antiquities: Classical Greek Art (5th-4th centuries BC). Disponível em: https://www.louvre. fr/en/oeuvre-notices/miniature-attic-red-figure-oinochoe. Acesso em 14/09/2020.

${ }^{20}$ Olpe (pl. olpai) - jarra utilizada para armazenar e servir vinho, que se distingue da oinochoe por ser alta em relação a sua largura e possuir alça elevada. Disponível em https://www.beazley.ox.ac.uk/tools/pottery/shapes/oinochoe.htm. Acesso em 12/01/2020.
} 
Figura 2 - Chous de figuras vermelhas, de aproximadamente 430 a.C.

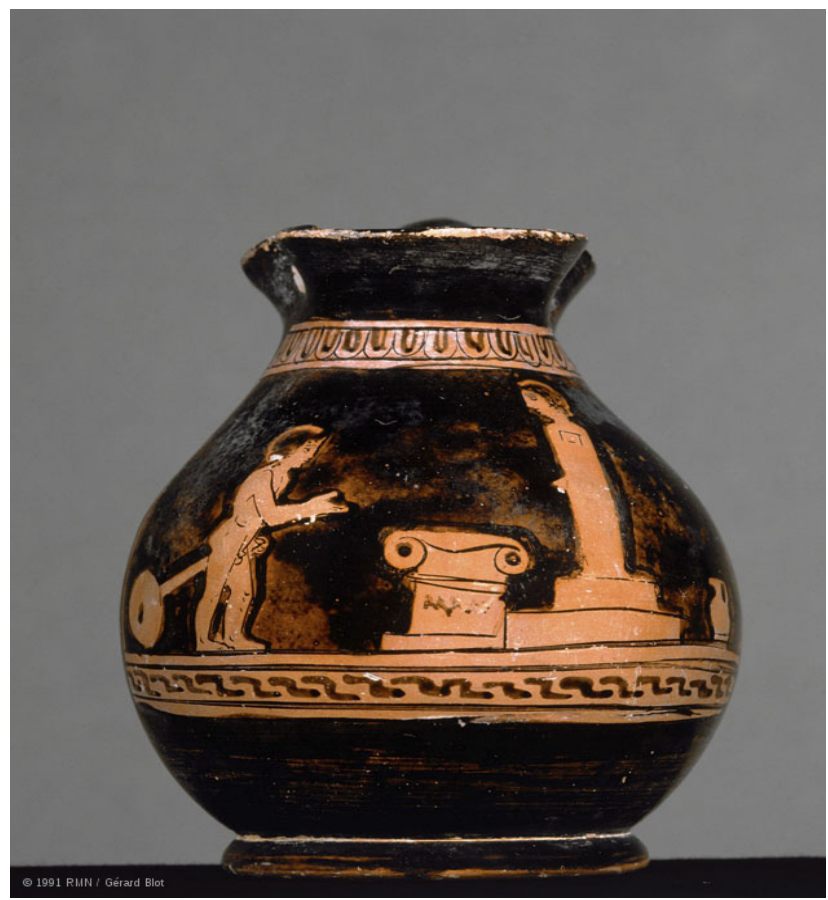

Atualmente no Museu do Louvre. Fotografia de (CRMN/Gérard Blot, 1991. Fonte: Museu do Louvre. Disponível em: https://www.louvre.fr/en/oeuvre-notices/miniature-attic-red-figure-oinochoe. Acesso em: 14 set. 2020 .

Conforme esclarece Kidd (2019, p. 109), carrinhos de brinquedo são frequentemente representados na cerâmica grega clássica, embora poucas peças tenham chegado aos dias atuais, em decorrência do cárater perecível da madeira. Os exemplares de brinquedos gregos antigos que dispomos nos museus foram produzidos por adultos para as crianças e não elaboradas por elas mesmas (SOMMER, 2011, p. 151). Entretanto, é interessante destacar que as crianças poderiam confeccionar seus próprios brinquedos, como por exemplo Fidípedes, em As Nuvens (877-882), descrito por seu pai a Sócrates como muito esperto por construir diversos modelos quando pequeno:

ESTREPSÍADES - Não se preocupe. Ensine-o. É um rapaz esperto por natureza. Desde criancinha, quando era deste tamanhinho, modelava casas, esculpia navios, fabricava carrinhos de tiras de couro e fazia sapos de miolo de pão.

Conforme dito anteriormente, na ausência de brinquedos por falta de recursos, ou mesmo para variar seu arsenal, as próprias crianças poderiam elaborar seus objetos de diversão, reforçando e recriando sua visão de mundo através das brincadeiras. Kishimoto (2011, p. 21) afirma que o brinquedo indica um mundo imaginário da criança que o manipula e também do adulto que o criou, variando de acordo com a idade: até os 
três anos os brinquedos estão carregados de animismo; de cinco a seis anos, possuem elementos da realidade.

Figura 3 - Chous de figuras vermelhas, de aproximadamente 420-400 a.C.

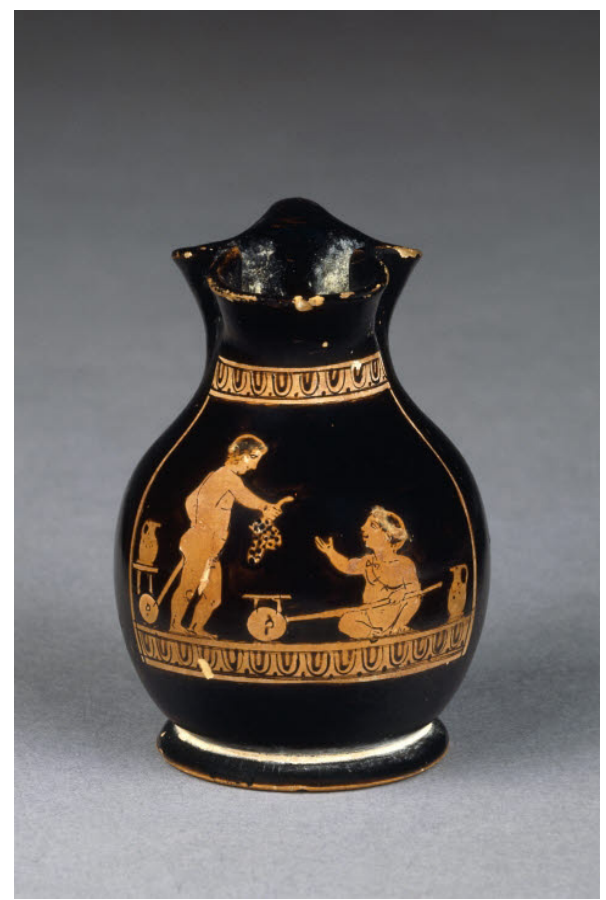

Fonte: Atualmente no Museu Britânico de Londres. E536.

Na terceira chous analisada neste artigo (Figura 3), são representados, com traços finos e minuciosos, dois meninos brincando com seus carrinhos ( $\dot{\alpha} \mu \alpha \xi \dot{\xi}(\zeta$, hamaxis): um em pé, do lado esquerdo da cena, que oferece um cacho de uvas o outro menino sentado, usando uma coroa, que está com o braço direito estendido. Ao fundo da cena existem duas oinochoai, uma sobre o chão, à direita, e outra sobre o carrinho, à esquerda. O contexto representado está claramente relacionado às Antestérias, especialmente pela presença do cacho de uvas, da coroa de flores na cabeça do menino sentado e das oinochoai.

Sobre a participação das crianças no festival, Cerqueira (2011, p. 154) esclarece que diversos jogos e brincadeiras ocorriam, conforme observamos no trecho a seguir:

As crianças envolviam-se em uma série de brincadeiras ou jogos, pois, afinal, uma parte significativa da festa era destinada a elas - a criança tinha função importante por ser um culto de vegetação, uma vez que ela simbolizava na comunidade os novos frutos, ela era a floração, o novo vinho. Garotinhos brincavam de efebos e adultos, correndo e dançando tal qual foliões, com suas khóes cheias de vinho. Recebiam presentes dos mais velhos, tais como as pequenas khóes (canequinhas), cachorrinhos ou brinquedos, sobretudo carrinhos, utilizados em brincadeiras registradas na cerâmica ática. 
Considerando as figuras acima, fica evidente a importância da interação entre as crianças através das brincadeiras e da participação destas no mundo adulto por meio de sua atuação nas Antestérias. Concordamos com a afirmação de Kishimoto (2011, p. 21) de que "duplicando diversos tipos de realidades presentes, o brinquedo metamorfoseia e fotografa a realidade. Não produz apenas objetos, mas uma totalidade social". Tanto na Figura 2 quanto na Figura 3, os brinquedos em cena proporcionam às crianças a assimilação dos valores impressos durante o festival em honra a Dioniso, haja vista, em ambas, os meninos reproduzirem ações próprias do ritual, tais como a contemplação do pilar hermaico, o transporte dos vasos de armazenamento do vinho e do compartilhamento dos cachos de uvas.

Após analisar as imagens de crianças brincando, presentes nas choes de figuras vermelhas do período clássico, e as reflexões platônicas, presentes no diálogo Leis, concluímos que os antigos atenienses consideravam os jogos e as brincadeiras atividades indissociáveis do universo infantil, haja vista o próprio vocábulo "brincadeira" (paidiá) estar etimologicamente enraizado no termo "criança" (pais). Ainda que a maior parte da sociedade não refletisse sobre a relação entre o brincar e o aprender, como o fez o filósofo Platão, esta reconhecia a relevância dos brinquedos no cotidiano infantil, a julgar pelas numerosas representações de brinquedos presentes nas choes encontradas nos túmulos de crianças e dos variados exemplares que chegaram até a atualidade.

\section{Referências}

\section{Documentação textual}

ARISTÓFANES. As Nuvens. Tradução de G. M. R. Starzynski. São Paulo: Difel, 1967.

ARISTOPHANE. Les Acharniens. Les Cavaliers. Les Nuées. Traduit par H. Van Daele. Paris: Les Belles Lettres, 1960.

BRASIL. RESOLUÇÃO CNE/CEB No 5, DE 17 DE DEZEMBRO DE 2009. Disponível em: http://www.crmariocovas.sp.gov.br/Downloads/ccs/concurso_2013/PDFs/resol_ federal_5_09.pdf. Acesso em 10/09/2020.

BRASIL. Base Nacional Curricular Comum (BNCC). Brasília: MEC/CONSED/UNDIME, 2017. Disponível em: http://basenacionalcomum.mec.gov.br/images/BNCC_EI_ EF_110518_versaofinal_site.pdf. Acesso em: 10/09/2020.

FÍlON DE ALEXANDRIA. Obras Completas. Traducción de J. M. Triviño. Buenos Aires: Acervo Cultural, 1975.

PLATÃO. A República. Tradução de Edson Bini. São Paulo: Edipro, 2019. 
PLATÃO. Leis. Tradução de C. H. Gomes. Lisboa: Edições 70, 2004. v. 1.

PLATÃO. Leis. Tradução de C. H. Gomes. Lisboa: Edições 70, 2019. v. 2.

PLATON. La République. Traduit par É. Chambry. Paris: Les Belles Lettres, 1949.

PLATON. Protagoras. Traduit par A. Croiset. Paris: Les Belles Lettres, 2002.

\section{Documentação visual}

KARDIANOU-MICHEL, A. Miniature Attic Red-Figure Oinochoe. Louvre - Department of Greek, Etruscan, and Roman Antiquities: Classical Greek Art (5th-4th centuries BC). Disponível em: https://www.louvre.fr/en/oeuvre-notices/miniature-attic-redfigure-oinochoe. Acesso em: 14/09/2020.

\section{Obras de apoio}

ANTUNES, C. O jogo e a Educação Infantil: falar e dizer, olhar e ver, escutar e ouvir. Petrópolis: Vozes, 2014.

BARROS, G. N. M. O espaço educativo na cidade de As Leis. In: FLORENZANO, M. B.; HIRATA, E. F. V. (org.). Estudos sobre a cidade antiga. São Paulo: Editora da Universidade de São Paulo, 2009. p. 53-75.

CAMBIANO, G. Tornar-se homem. In: VERNANT, J. P. (org.). O homem grego. Lisboa: Presença, 1994, p. 75-101.

CANFORA, L. O cidadão. In: VERNANT, J-P. (org.). O homem grego. Lisboa: Presença, 1994, p. 103-129.

CERQUEIRA, F. V. As Antestérias, um ritual carnavalesco de transgressão e afirmação da ordem social na antiga Atenas (séc. VI e V A.C.). Patrimônio e Memória, v. 7, n. 1, p. 151-171, 2011.

CÓRIA SABINI, M. A.; LUCENA, R. F. Jogos e brincadeiras na educação infantil. Campinas: Papirus, 2012.

DASEN, V. Histoire et archéologie de la culture ludique dans le monde gréco-romain: questions méthodologiques. Kentron, n. 34, p. 23-50, 2018.

DORIA, F.; GIUMAN, M. The swinging woman: Phaedra and swing in Classical Greece. Medea, v. 1, n. 2, p. 1-34, 2016.

FERREIRA, L. N. Crianças na arte grega: representações sociais e convenções artísticas. In: SOARES, C. et. al. (org.). Norma \& transgressão. Coimbra: Imprensa da Universidade de Coimbra, 2011, p. 59-95. v. 2. 
FERREIRA, L. N.; RODRIGUES, N. S. Tornar-se adulto na Antiguidade Clássica. In: FONSECA, A. C. (org.). Jovens adultos. Coimbra: Almedina, 2014, p. 87-130.

GARCIA, R. M. R.; MARQUES, L. A. Brincadeiras cantadas. Porto Alegre: Kuarup, 1990.

GARLAND, R. Children in Athenian religion. In: GRUBBS, J. E.; PARKIN, T. (ed.). Oxford handbook of childhood and education in the Classical World. New York: Oxford University, 2013, p. 207-226.

GOLDEN, M. Children and childhood in classical Athens. Baltimore: Johns Hopkins University, 2015.

GOMES, C. H. Introdução. In: PLATÃO. Leis. Lisboa: Edições 70, 2004, p. 7-57.

GRIMAL, P. Dicionário da mitologia grega e romana. Rio de Janeiro: Bertrand Brasil, 1992. HAM, G. L. The choes and Anthesteria reconsidered: male maturation rites and the Peloponnesian Wars. In: PADILLA, M. W. (ed.). Rites of passage in Ancient Greece: literature, religion, society. Lewisburg: Bucknell University Press, 1999, p. 201-218.

KIDD, S. E. Play and aesthetics in Ancient Greece. Cambridge: Cambridge University Press, 2019.

KISHIMOTO, T. M. O jogo e a educação infantil. In: . (org). Jogo, brinquedo, brincadeira e a educação. São Paulo: Cortez, 2011, p. 15-48.

LESKY, A. História da literatura grega. Lisboa: Fundação Calluste Gulbenkian, 1995.

LYNCH, K. M.; PAPADOPOULOS, J. K. Sella cacatoria: a study of the potty in Archaic and Classical Athens. Hesperia, v. 75, n. 1, p. 1-32, 2006.

MARROU, H. I. História da Educação na Antiguidade. São Paulo: EPU, 1990.

MOSSÉ, C. Dicionário da Civilização Grega. Rio de Janeiro: Jorge Zahar, 2004.

NEILS, J.; OAKLEY, J. (ed.). Coming of age in Ancient Greece: images of childhood from the classical past. New Haven: Yale University Press, 2003.

OAKLEY, J. H. Children in Archaic and Classical Greek Art: a survey. In: GRUBBS, J. E.; PARKIN, T. (ed.). Oxford handbook of childhood and education in the Classical World. New York: Oxford University Press, 2013, p. 147-171.

PARKE, H. W. Festivals of the Athenians. New York: Cornell University Press, 1994.

QUEIROZ, J. F.; SANTOS, L. O advento da Base Nacional Comum Curricular sob as perspectivas teórico-epistemológicas de Piaget, Wallon e Vygotsky. Semana Acadêmica, n. 160, v. 1, p. 1-14, 2019.

SOMMER, M. S. Toys, play and swaddling: indications of early childhood in Ancient Greece. In: FAHLANDER, F. (ed.). Spåren av de små: arkeologiska perspektiv på barn och barndom. Stockholms: Stockholms universitet, 2011, p. 145-159. 
SOUSA, L. N. Havia entre os atenienses do período clássico a ideia de infância? Uma possibilidade de análise do diálogo entre a cerâmica grega e a Filosofia. Revista de História da UEG, n. 8, v. 2, p. 1-19, 2019.

VEGETTI, M. O homem e os deuses. In: VERNANT, J. P. (org.). O homem grego. Lisboa: Presença, 1994, p. 229-253. 